\title{
Correction to: Conservative Sinusectomy vs. excision and primary off-midline closure for pilonidal disease: a randomized controlled trial
}

Sotirios Georgios Popeskou ${ }^{1}$ - Barbara Pravini ${ }^{2}$ - Sofoklis Panteleimonitis ${ }^{3}$ - Antoniacopo Ferrario di Tor Vajana ${ }^{4}$. Alice Vanoni ${ }^{5} \cdot$ Mike Schmalzbauer $^{2}$ - Alberto Posabella ${ }^{6}$ - Dimitri Christoforidis ${ }^{2,7,7}$

Published online: 26 May 2020

(C) Springer-Verlag GmbH Germany, part of Springer Nature 2020

\section{Correction to: International Journal of Colorectal Disease} https://doi.org/10.1007/s00384-020-03551-9

The original version of this article, unfortunately, contained an error. The given names and family names of the authors were interchanged and are now presented correctly. The original article has been corrected.

The online version of the original article can be found at https://oi.org/ $10.1007 / \mathrm{s} 00384-020-03551-9$

Sotirios Georgios Popeskou

salvator10@yahoo.com

$\bowtie$ Dimitri Christoforidis

dimitri.christoforidis@eoc.ch

1 Department of Visceral Surgery and Transplantation, Geneva University Hospitals, Geneva, Switzerland

2 Depatment of Surgery, Regional Hospital of Lugano, Lugano, Switzerland

3 School of Health Sciences and social work, University of Portsmouth, Portsmouth, UK
4 Department of Surgery, Regional Hospital of Bellinzona, Bellinzona, Switzerland

5 Department of Visceral Surgery, Lausanne University Hospital, Lausanne, Switzerland

6 Department of Surgery, Standort Unispital Clarunis, Universitäres Bauchzentrum Basel, Basel, Switzerland

7 Lausanne University Hospital and University of Lausanne, Vice-Primario, Chirurgia, Ospedale Regionale di Lugano, via Tesserete 42, 6900 Lugano, Switzerland 